\title{
Correction to: Assessing the effects of an empathy education program using psychometric instruments and brain fMRI
}

\author{
Kangmoon $\mathrm{Kim}^{1}$ · Sang Hee Kim² ${ }^{2}$ HeungSik Yoon ${ }^{2} \cdot$ Hyoung Seok Shin ${ }^{1}$. \\ Young-Mee Lee ${ }^{1}$ (D)
}

Published online: 16 October 2019

() Springer Nature B.V. 2019

\section{Correction to: Advances in Health Sciences Education https://doi.org/10.1007/s10459-019-09918-0}

Due to an unfortunate turn of events, the funding note was omitted from the original publication. The correct funding note is published here and should be treated as definitive.

Funding This research was supported by the National Research Foundation of Korea (NRF), grant funded by the Korea Government (MSIT) (R1A2B4013614).

Publisher's Note Springer Nature remains neutral with regard to jurisdictional claims from published maps and institutional affiliations.

The original article can be found online at https://doi.org/10.1007/s10459-019-09918-0.

Young-Mee Lee

ymleehj@korea.ac.kr

1 Department of Medical Education, Korea University College of Medicine, 73 Inchon-ro,

Seongbuk-gu, Seoul 02841, Korea

2 Department of Brain and Cognitive Engineering, Korea University, Seoul, Korea 